\title{
Coalizões em disputas eleitorais: notas a partir de um caso do nordeste brasileiro
}

João Gilberto do Nascimento Lima ${ }^{1}$

A análise que segue, centrada no estado do Maranhão, objetiva captar a constituição e acionamento sucessivo em disputas eleitorais de um conjunto de relações que envolve agentes situados nos diferentes planos da hierarquia política (municipal, estadual e federal). 0 intuito é demonstrar como, a partir de dois momentos de rearranjos significativos nas disputas entre as facções que concorrem no plano estadual, ocorreram recomposições nas alianças estabelecidas entre as "lideranças" pelo interior do estado, tomando as bases sobre as quais estes vínculos foram formados e desfeitos, bem como as justificativas dadas para os mesmos. Somando-se a isso, são apresentados alguns desempenhos eleitorais de candidatos que compõem tais relações a diferentes cargos eletivos e em pleitos distintos, visando perceber até que ponto os esforços no sentido da conquista de aliados podem efetivamente se converter em votos. Desse modo, pretende-se contribuir para as investigações das formas de mobilização e concepções da atividade política em contextos como o brasileiro.

Palavras-chave: Redes Sociais. Coalizões. Dominação Política. Processos Eleitorais. 


\title{
Coalitions in electoral disputes: notes from a case of northeastern Brazil
}

\begin{abstract}
The study that follows, centered in the state of Maranhão, aims to understand the constitution and the continuously triggering of a set of relations involving the agents of municipal, state and national levels. Starting with two rival factions at the state level on two different periods at the electoral race, and taking into account the grounds under which those bounds are made and undone as well as their justifications, the goal is to demonstrate how the coalitions, set by their respective leaderships, take place. In addition, and in a way to elucidate the extent to which point the efforts to gather allies will be reverted into votes, the electoral performance of the candidates in some of those relations are shown. Therefore, one hopes to contribute to the studies of mobilization and on the concepts of political phenomena in the brazilian context.
\end{abstract}

Key-words: Social Networks. Coalitions. Political Domination. Electoral Process.

Os processos eleitorais se apresentam como momentos privilegiados para a observação e análise da atualização de lógicas que (re)definem o jogo político. Deste modo, encerram a possibilidade da renovação, ruptura ou criação de vínculos entre políticos situados nos diferentes planos de autoridade política, interferindo mesmo na própria dinâmica das relações que se estabelecem fora do período eleitoral (BEZERRA, 2006; PALMEIRA, 1996).

0 presente artigo tem um sentido estrito: perquirir, a partir de três eleições subsequentes (2006, 2008 e 2010), de que forma alianças entre políticos se estabeleceram pelo Maranhão, sob quais justificativas e que tipo de relações as mesmas possuíam com rearranjos importantes pelos quais passaram as relações de força que envolveram as facções que rivalizavam no plano es- 
tadual (a ruptura de José Reinaldo Tavares², então governador do estado, com a facção liderada pela "família" Sarney, a composição da chamada "Frente de Libertação do Maranhão" e a vitória de Jackson Lago $^{3}$ para governador, em 2006, e a sua cassação e posse de Roseana Sarney ${ }^{4}$ no mesmo cargo, em 2009), direcionando o olhar para a constituição de cadeias de líderes-seguidores (LANDÉ, 1977) que tornam interdependentes os níveis da hierarquia política.

O foco recai sobre a rede articulada em torno de Humberto Cou-
tinho ${ }^{5}$ e os modos pelos quais a mesma foi mobilizada para a
eleição de duas "dobradinhas"6, uma em 2006 (Flávio Dino7 /

2 Engenheiro (UFC, 1964) e economista (PUC-Rio, 1970). Ex-deputado federal (19911995) pelo PFL. Ocupou vários cargos públicos de "primeiro escalão", dentre eles: Diretor-geral do DER, em São Luís; Secretário de Planejamento do Estado do Maranhão; Secretário de Viação e Obras, em Brasília; Diretor-geral do DNOS, no Rio de Janeiro; superintendente da SUDENE, em Recife. Foi ainda ministro dos Transportes (1986-1990) e vice-governador do estado do Maranhão nos períodos de 1995 a 1998 e de 1999 a 2002. Neste último ano, assumiu o governo do estado, se reelegendo pelo PTB e governando até 2006.

3 Médico. Ex-prefeito de São Luís (1989-1992 e 1997-2002) e ex-governador do Maranhão (2007-2009). Foi um dos fundadores, em 1979, do diretório nacional do PDT.

4 Socióloga (UnB) e funcionária pública, natural de São Luís, filha de José Sarney e Marly Macieira Sarney. Foi deputada federal (1991-1995), governadora do estado (19952002). Foi ainda senadora e líder do governo no Congresso Nacional. Voltou a governar o estado em 2009.

5 Ex-prefeito do município de Caxias, filiado ao PDT e importante "liderança" do "interior" do estado, eleito em 2004 e reeleito em 2008 com o auxílio de conexões "para cima" e "para baixo" nos planos do jogo político. Foi ainda vereador de Caxias (eleito em 1988), deputado estadual por quatro mandatos e candidato a prefeito do mesmo município em 2000, quando foi derrotado por seus adversários locais.

6 Categoria nativa que designa alianças que visam eleger dois políticos para cargos distintos numa mesma eleição (no caso em pauta, para os cargos de deputado federal e estadual).

7 Ex-juiz federal e ex-deputado federal (2007-2011), filiado ao PC do B. Foi candidato à prefeitura de São Luís em 2008 e ao governo do estado em 2010. Atualmente preside a EMBRATUR e é cotado como um dos principais candidatos ao cargo de governador do Maranhão nas eleições de 2014. 
Cleide Coutinho $^{8}$ ) e outra nas eleições de 2010 (Nice Lobão ${ }^{9}$ Cleide Coutinho), e de candidatos ao Senado e ao governo do estado, observando-se as variações que as relações estabelecidas pelo ex-prefeito em pauta sofreram entre 2006 e 2010.

Objetivamos trabalhar simultaneamente com uma perspectiva sincrônica, que consiga perceber as gramáticas que são mobilizadas nas interfaces da "grande política" com a "pequena política", observando a dinâmica que se estabelece entre as relações institucionais e as relações pessoais nos diferentes níveis do jogo político (PALMEIRA, 2006; BEZERRA, 2006; WOLF, 2003b) e uma abordagem diacrônica, que por sua vez permita cotejar as mudanças ocorridas nas relações de poder pelo estado e nas coalizões em questão (WEINGROD, 1986; BOISSEVAIN, 2003; MAYER, 1987) ${ }^{10}$.

Dentre os recursos e princípios de legitimação (CORADINI, 2008) presentes nas disputas eleitorais, a demonstração de

8 Médica formada pela UFBA e esposa de Humberto Coutinho. Ex-vice-prefeita de Caxias e deputada estadual em segundo mandato. Filiada ao PSB.

9 Servidora pública. Natural de Recife (PE). Atualmente é deputada federal, filiada ao DEM, exercendo o cargo seguidamente desde 1999. Esposa de Edison Lobão, candidato ao Senado em 2010 e atual ministro das Minas e Energia, filiado ao PMDB.

10 Essas pretensões são operacionalizadas por meio de uma série de categorias de análise fundamentais, que foram desenvolvidas e aprimoradas sobretudo nos estudos de antropologia política (com particular ênfase àqueles empiricamente situados no Mediterrâneo). Noções como as de grupos diádicos não-corporados, coalizões, facções, cadeias de líderes-seguidores, quase-grupos, conjuntos-de-ação, que são, por definição, agrupamentos mobilizados a partir de um ego ou clique, caracterizando-se pela instabilidade das relações estabelecidas (incerteza quanto à sua continuidade), pela falta de um conteúdo e de objetivos comuns (busca da realização de metas pessoais), bem como pelas rivalidades que se estabelecem destes com outros agrupamentos semelhantes, constituem-se em importantes ferramentas para a decodificação da pluralidade das bases que sedimentam as relações que serão aqui descritas e analisadas. Entretanto, é bastante pertinente consultar a reflexão de Marques (1999) sobre a rotinização dos achados de pesquisa da "antropologia do Mediterrâneo" e os problemas oriundos dessa postura. Apesar de muito fecunda, a noção de quase-grupo, tal como definida por Mayer (1987), é passível de críticas. Ver, nesse sentido, Boissevain (1971). 
alianças "para cima" e "para baixo" ocupa um lugar central nas representações e estratégias dos candidatos tanto a cargos municipais quanto a funções nas alçadas estadual e federal, o que conformaria a chamada "força política", que se refere precisamente à capacidade de exercer a função de mediador ${ }^{11}$ entre as demandas "locais" e os recursos públicos, bem como à constituição de reputações (BEZERRA, 2006; GRILL, 2008).

Diante disto, podemos nos interrogar acerca do estudo da política - e/ou dos "políticos" - em contextos periféricos, como no caso do estado do Maranhão. Temos condições então de observar em operação linguagens de legitimação destas relações baseadas em registros com matrizes bastante difusas, indo desde critérios como as vinculações partidárias até o parentesco, a lealdade, a amizade, apresentando-se, muitas vezes, como relações de dependência pessoal e de dominação (BEZERRA, 2006; BOURDIEU, 2006).

O que está em jogo, fundamentalmente, é a capacidade da conversão destas relações fundadas em bases múltiplas para fins de conquista de votos visando eleger os candidatos aliados de Humberto Coutinho (assim como para legitimar sua própria candidatura a prefeito de Caxias no ano de 2008). Portanto, a análise empreendida visa apreender o nível de politização desses laços (FRETEL e LAGROYE, 2005), bem como as possibilidades e limites para essa conversão ${ }^{12}$.

11 Consideramos a mediação como sendo a comunicação entre a parte e o todo (WOLF, 2003a), articulando-se espaços separados por linguagens e códigos e regras distintos, mas que se complementam (VELHO e KUSCHNIR, 2000), configurando um duplo horizonte de práticas e de relações, que possui lógicas tanto do "local" como do "nacional", que influi nos papéis constituintes do métier político (LAGROYE, 1993 e 1994) e na implantação local dos recursos acumulados nesse trânsito, quando das candidaturas a cargos eletivos (BRIQUET e SAWICKI, 1989).

12 Como destaca Coradini (1997, p.5), o efeito de objetivação social dos resultados eleitorais torna imprescindível a sua análise, não por princípios normativos e/ou de avaliação do maior ou menor êxito deste ou daquele candidato na sua empreitada eleitoral, mas 


\section{A "Frente de Libertação do Maranhão"}

Partindo da exposição do conjunto de realinhamentos ocorridos na dinâmica faccional do estado, observado principalmente a partir das eleições gerais de 2006 e 2010, serão considerados os movimentos dos agentes em pauta, as adesões e rupturas, as justificativas mobilizadas e os impactos dessa dinâmica na conquista e ampliação de bases eleitorais por parte dos candidatos analisados.

Uma das virtudes da análise que segue é poder levar em conta, de modo longitudinal, o acionamento sucessivo de conjuntos-de-ação (MAYER, 1987), cotejando as suas transformações e relações com o espaço mais amplo da competição política. Tal empreendimento é realizado de modo cumulativo, por meio de seguidos trabalhos desenvolvidos que tomaram um conjunto de relações semelhante como objeto, a partir de diferentes egos.

O primeiro destes estudos é o de Barros Filho (2008), que analisou de forma detalhada a candidatura de Flávio Dino (atualmente um dos principais aliados de Humberto Coutinho no plano estadual) para deputado federal no processo eleitoral de 2006, percebendo as estratégias avançadas por este agente para a "entrada” no município de Caxias, ou seja, para torná-lo (ao município e à "região" que o compreende) sua principal base eleitoral no "interior" do estado. Segundo este autor, Flávio Dino foi apresentado a Humberto Coutinho por José Reinaldo Tavares, amigo de longa data do então prefeito de Caxias.

sim porque seus efeitos são concretos sobre as disputas políticas. Em suas palavras, "os resultados e também os alinhamentos eleitorais anteriores ou presumidos condicionam as possibilidades de estratégias dos candidatos ou das elites políticas envolvidas, bem como as possibilidades de 'opções' dos eleitores em potencial. Dessa objetivação social dos resultados eleitorais, que se transfigura não apenas em 'vitórias' ou 'derrotas', mas também na estruturação das clivagens e oposições entre facções, posições partidárias ou mesmo candidaturas, o que mais interessa (...) são seus usos sociais, ou seja, as formas igualmente estruturadas de manipulação coletiva dos 'universos práticos' e suas lógicas”. 
O segundo trabalho foi realizado tendo como recorte as eleições municipais de 2008, a partir da candidatura de Humberto Coutinho para prefeito (LIMA, 2010). Aqui, foi possível observar como a vinculação com Flávio Dino (melhor descrita a seguir) foi utilizada desta vez por Humberto, na busca pela legitimidade da sua condição de candidato, do mesmo modo que o vínculo com sua esposa, Cleide Coutinho, eleita em 2006 para deputada estadual, "trabalhando na Assembleia por Caxias", como era insistentemente apresentado o seu trabalho nos materiais de campanha e nos programas do Horário Eleitoral Gratuito ${ }^{13}$.

As principais transformações das redes de relações que serão tratadas adiante são tributárias da ruptura de José Reinaldo Tavares com a facção liderada pela "família" Sarney, em um movimento que aglutinou diferentes "lideranças" políticas do estado (dentre elas, Jackson Lago e Edson Vidigal ${ }^{14}$ ) no que ficou conhecida como a "Frente de Libertação do Maranhão", que visava alijar a coalizão da "família" Sarney do poder.

Uma das principais alianças "para cima" que dispunha Humberto Coutinho era com José Reinaldo. No movimento rumo à oposição por parte do segundo, Humberto Coutinho efetua (levando consigo o conjunto de relações que controlava a nível "local” ${ }^{15}$ ) o mesmo caminho. Como veremos, essas mudanças causadas pela ruptura em pauta terão impacto direto na constituição das alianças em todos os níveis de disputa política nos processos eleitorais considerados.

13 Como desdobramento e avanço dessa última pesquisa, nossa dissertação de mestrado tomou o mesmo conjunto de relações em perspectiva, analisando sua configuração de 2006 a 2010 (LIMA, 2012).

14 Natural de Caxias (MA). Ex-ministro do STJ e candidato ao governo do estado em 2006, apoiado por Humberto Coutinho.

15 Para investigações do processo de ascensão e afirmação político-eleitoral de Humberto Coutinho em Caxias e no estado, ver Lima (2010 e 2012). 
O conjunto das vinculações entre Humberto Coutinho (e consequentemente da facção que o mesmo liderava) e demais agentes políticos foi apreendido através das entrevistas realizadas e de materiais de campanha, além dos achados de pesquisa de Barros Filho (2008).

Dados os limites do presente texto, priorizaremos a constituição da aliança envolvendo Humberto Coutinho (e seu conjunto de seguidores) e Flávio Dino, as interpretações da mesma, as expectativas mútuas com ela (BEZERRA, 2006), os registros sob os quais é enunciada e as relações da mesma com as votações obtidas por Flávio Dino e Cleide Coutinho nas eleições de 2006 e 2010.

Como já expusemos, Humberto Coutinho possui uma relação relativamente antiga com José Reinaldo Tavares, que à época das eleições de 2006 era o governador do estado do Maranhão. Flávio Dino foi por ele apresentado a Humberto. Após a apresentação e constituição do vínculo mediado por José Reinaldo, Flávio Dino compôs a chamada "dobradinha" com Cleide Coutinho nesta eleição (o primeiro para deputado federal e a segunda para deputada estadual).

Antes mesmo de ser eleito deputado federal, ainda na sua pré-candidatura, Flávio Dino já havia conseguido destinar recursos do governo federal para a cidade de Caxias, o que contribuiu para consolidar a relação entre Humberto Coutinho e Flávio Dino e foi algo recorrentemente acionado para construir a imagem do então pretendente ao cargo de deputado federal frente às "lideranças" e eleitores de Caxias como alguém que "consegue as verbas que Caxias precisa".

A tônica dos usos políticos dessa aliança nos processos eleitorais analisados é a capacidade potencial da busca dos recursos na alçada federal e a sua efetivação em obras na cidade. Com recursos destinados por Flávio Dino para Caxias antes mesmo 
de se tornar deputado, o empenho de Humberto Coutinho na sua eleição aparece como uma retribuição. Como explicitou Barros Filho (2008), além das tentativas de vinculação pessoal de Flávio Dino com a cidade (afirmando que em Caxias sua esposa nasceu e foi criada, por exemplo), a principal estratégia utilizada com fins a tornar Caxias em sua base eleitoral foi a força enquanto mediador, como alguém que tem "reputação", amizades e contatos com agentes localizados nos Ministérios. Esse "prestígio" acumulado serviria para enfatizar a capacidade de trânsito de Flávio Dino pelos "centros" de poder, o que faria com que a "região de Caxias" estivesse bem representada no cenário nacional, já que suas demandas, por meio do então candidato a deputado federal, seriam atendidas.

A ativação da rede de apoiadores de Humberto Coutinho fez com que ocorresse, de maneira bem sucedida, a implantação de Flávio Dino na "região" enquanto candidato, já que seu desempenho eleitoral final na sua campanha para deputado federal contou com massiva contribuição dos votos daí oriundos. Do mesmo modo, as votações de Cleide Coutinho são destacadas nos municípios nos quais Humberto Coutinho tinha aliados em $2006^{16}$.

Os municípios que passaram a figurar nas votações de Cleide Coutinho e que não estiveram presentes nos resultados eleitorais de Humberto Coutinho nas suas campanhas para deputado estadual em eleições anteriores são: Paraibano, onde Cleide conseguiu 16,87\% dos votos da cidade, representando 6,49\% do seu desempenho global; Santa Filomena do Maranhão, que registrou, dentre todos as cidades analisadas, a maior predominância da candidatura de Cleide Coutinho junto ao seu eleitorado, com 78,12\% dos votos válidos e 2,89\% na sua votação geral;

16 Para analisar os desempenhos eleitorais, consideramos aqueles municípios onde as votações obtidas representaram, nos colégios eleitorais, parcelas próximas ou acima de $10 \%$ dos votos ou onde, por meio dos relatos colhidos, tomou-se conhecimento de importantes alianças mantidas por Humberto Coutinho. 
Pedreiras, com 6,61\% dos sufrágios da cidade que se refletiram em 2,32\% do total; e Paço do Lumiar, com 3,61\% eleitorado do município e 2,09\% somando-se ao seu resultado final.

Além da expansão das bases eleitorais da "família" Coutinho para outras cidades do "interior" do estado, os dados permitem identificar uma tendência geral de afirmação maior nos municípios onde os desempenhos já eram significativos em 1998 e 2002 (anos de campanhas de Humberto Coutinho para deputado estadual). Desse modo, retomando alguns números, temos que Humberto Coutinho contabilizou em Caxias, nos anos de 1998 e 2002, 9,88\% e 20,53\% dos votos válidos da cidade, respectivamente. Na mesma cidade, mas em 2006, Cleide Coutinho confirma a curva ascendente e registra uma fatia de 38,41\% dos votos do eleitorado caxiense. Em São Domingos do Maranhão, Humberto Coutinho deteve 13,55\% do eleitorado em seu desempenho de 1998. Em 2002, este número caiu para 7,18\%. Em 2006, as votações nesse município voltam a se elevar e na candidatura de Cleide Coutinho chegam a 35,41\% dos votos da cidade. De modo semelhante, em Tuntum também se evidencia um crescimento: nas candidaturas de Humberto Coutinho, os coeficientes subiram de 26,89\% (1998) para 37,17\% (2002) dos votos válidos, sendo que Cleide Coutinho obteve quase a metade dos votos da cidade $(48,48 \%)$ na eleição de $2006^{17}$.

Ainda no que tange às parcelas do eleitorado atingidas nas cidades pelas candidaturas de Humberto e Cleide Coutinho, em Matões (município onde boa parte dos irmãos da "família" Coutinho nasceu e no qual Eugênio Coutinho ${ }^{18}$ possuía muitas terras - que até

17 A maior parte dos municípios aqui apresentados como importantes bases eleitorais da "família" Coutinho e de seus aliados estão situados na região leste do estado, cuja principal cidade é Caxias.

18 Pai de Humberto Coutinho. Foi vereador de Matões e candidato a prefeito na década de1950, não obtendo êxito. Foi também prefeito por curto período de tempo da cidade de Parnarama, emancipada à época da cidade de Matões. 
hoje existem e foram divididas entre os irmãos) as votações deste casal se mostraram sempre consideráveis ao longo do tempo. Neste município, Humberto registrou os índices de 18,90\% em 1998 e 29,48\% em 2002. Por sua vez, Cleide Coutinho conseguiu atingir $17,54 \%$ dos votos da população matoense em 2006. Na mesma linha, Parnarama (município "fundado" por Eugênio Coutinho e que compõe, juntamente com Caxias e Matões, a "região de origem" da "família" Coutinho ${ }^{19}$ ) se mostra como uma importante base eleitoral para estes protagonistas políticos, na medida em que observa que em 1998, Humberto alcançou 18,69\% e em 2002 conquistou $27,30 \%$ dos votos dos parnaramenses, enquanto que em 2006 o desempenho de Cleide Coutinho foi de $23,10 \%$ na cidade.

Nestes municípios, embora as votações de Humberto e Cleide Coutinho sejam expressivas, observam-se quedas nos coeficientes obtidos entre as eleições de 2002 e 2006. Em Matões, passou-se de 29,48\% (2002) para 17,54\% (2006) e em Parnarama o desempenho saiu de 27,30\% em 2002 para 23,10\% em 2006. No entanto, estes números precisam ser interpretados à luz das mudanças ocorridas ao longo do tempo nos colégios eleitorais dos municípios (que, de maneira geral, cresceram) e considerando os números absolutos das votações alcançadas. Assim, ainda que as porcentagens apresentem ligeira diminuição, os valores absolutos ainda apresentam tendência de crescimento: em 1998, Humberto Coutinho totalizou 26.793 votos, indo para 27.152 na eleição de 2002. Os números totais referentes à candidatura de Cleide Coutinho em 2006 ultrapassam o dobro do total obtido por Humberto na eleição geral anterior, contabilizando 56.634 votos. Nunca é demais lembrar que Humberto Coutinho já havia sido eleito prefeito de Caxias nessa época (foi eleito em 2004), assegurando uma posição dominante na "região", o que favoreceu a construção e ampliação de laços com prefeitos de outras cidades, que foram também fundamentais para a eleição de Flávio Dino para deputado federal. 
No processo eleitoral em pauta (2006), Humberto Coutinho esteve em vários municípios do estado onde possuía aliados, empenhado na eleição da "dobradinha" Flávio Dino/Cleide Coutinho. Barros Filho (2008) identificou como principais municípios onde se operou a mediação de Humberto Coutinho para estes candidatos as cidades de Caxias, Pedreiras, Santa Filomena do Maranhão, Matões, Parnarama, São Domingos do Maranhão, Tuntum e Paço do Lumiar.

O primeiro deles, Caxias, no qual Humberto Coutinho tem o seu maior conjunto de alianças, que vai desde vereadores até "lideranças" de bairros e povoados da cidade, Flávio Dino recebeu os votos de 44,63\% do seu eleitorado, coeficiente maior inclusive em relação ao que conseguiu Cleide Coutinho, que chegou a $38,41 \%$.

Na cidade de Pedreiras, o vínculo mediado por Humberto Coutinho foi com um ex-prefeito da cidade, além desse município ser o lugar de "origem" da "família" do atual procurador-geral de Caxias, membro da equipe de campanha de Humberto Coutinho no ano de 2004. Lá, além dos 6,61\% do eleitorado que votou em Cleide Coutinho, 11,10\% depositou seus votos na candidatura de Flávio Dino, o que representou 1,7\% no total dos votos que o mesmo obteve.

Em Tuntum, Tema Cunha foi a "liderança" da cidade a ser acionada. À época, ele era prefeito do município e presidente da Federação dos Municípios do Estado do Maranhão. Segundo Barros Filho (2008), a intermediação foi feita por Humberto Coutinho, mas também por Sálvio Dino (pai de Flávio Dino). Aqui, Flávio Dino teve $7,1 \%$ do seu total de votos, o que representou uma parcela de 48,18\% dos votos válidos da cidade.

No pequeno município de Santa Filomena do Maranhão, as relações mobilizadas para a eleição da "dobradinha" foram efetuadas com "lideranças locais" que possuíam vínculos não só com 
Humberto Coutinho, mas também com Tema Cunha. Indicadores da força e influência nas relações tecidas no município foram os $78,12 \%$ dos votos da cidade que Cleide Coutinho recebeu. Embora os números não tenham sido tão expressivos quanto esses, 43,57\% do eleitorado da cidade apostou na candidatura de Flávio Dino.

Município que compõe a "região de origem" da "família" Coutinho, onde o vice-prefeito (Edimundo Coutinho) e o presidente da Câmara Municipal (Ferdinando Coutinho) ${ }^{20}$ são irmãos de Humberto Coutinho, e onde a "família" também possui propriedades de terra desde Eugênio Coutinho e conta com o "controle" de um eleitorado razoável (20\%, segundo relato de Ferdinando Coutinho), Matões também é uma importante base eleitoral para a "dobradinha". Além das vinculações diretas dos membros da "família" Coutinho com a ocupação de posições políticas na cidade, ao longo do tempo os mesmos estabeleceram relações de aliança com diferentes facções políticas "mais fortes" do que eles no município.

Atualmente, os principais aliados na cidade são os membros da "família" Pereira, sobretudo Rubens Pereira e sua esposa e atual prefeita, Suely Pereira, de quem Edimundo Coutinho (irmão de Humberto Coutinho) era vice, e Rubens Pereira Júnior, filho de Rubens e Suely Pereira, deputado estadual filado ao PC do B (mesmo partido de Flávio Dino). Quando das eleições de 2006, a mobilização destas relações rendeu para Flávio Dino 9,84\% dos votos da cidade, que representou pouco mais de $1,00 \%$ do seu resultado global $(1,06 \%)$.

As relações de parentesco também foram acionadas no município vizinho a Matões, Parnarama. José Washington, primo dos irmãos da "família" Coutinho, é ex-vice-prefeito da cidade e sua esposa, Socorro Alves, atualmente é vereadora e presidente da 
Câmara Municipal. Outras alianças com "lideranças" na cidade (como o ex-prefeito, Davi) também foram mobilizadas. Flávio Dino teve aqui $2,6 \%$ dos seus votos, que compreendiam $21,17 \%$ dos votos válidos totalizados.

Em São Domingos do Maranhão, novamente Humberto Coutinho utilizou das suas relações para eleger a referida "dobradinha", desta vez juntamente com José Reinaldo Tavares (BARROS FILHO, 2008). A principal "liderança local” com a qual foi feita essa intermediação foi Kléber, o "Tratorzão”, como é popularmente conhecido. No momento eleitoral de 2006, Kléber era secretário regional do governo do estado. Em seguida, foi prefeito da cidade. Da votação geral de Flávio Dino, 5,6\% saíram de São Domingos. Em termos municipais, este candidato contou $38,34 \%$ dos votos do eleitorado local.

Por fim, em Paço do Lumiar (município que compõe a região metropolitana de São Luís), a relação mediada foi com Fred Campos, então vereador, que havia sido o mais votado da cidade na eleição municipal de 2004 e que se diz "filho político" de Humberto Coutinho (BARROS FILHO, 2008). Lá, 4,35\% dos votos foram para a candidatura de Flávio Dino.

Embora as votações de Flávio Dino pelo estado não sejam tão concentradas como as dos Coutinho (em relação ao número e localização geográfica dos municípios), percebe-se a grande presença da porção leste do estado na base eleitoral deste candidato. Como tentamos demonstrar, esta "região" é a mesma onde se assenta a maior parte do "reduto eleitoral" da "família" Coutinho, o que explicita a mediação das relações feita por Humberto Coutinho com "lideranças locais", quando da candidatura de Flávio Dino para deputado federal.

Outros elementos reforçam isso: em quatro municípios em que comparamos as votações de Cleide Coutinho e Flávio Dino (Tun- 
tum, São Domingos do Maranhão, Parnarama e Paço do Lumiar), temos uma proximidade grande entre os coeficientes eleitorais destes dois protagonistas, em relação ao conjunto dos votos válidos (respectivamente: Tuntum - 48,48\%/48,18\%; São Domingos do Maranhão - 35,41\%/38,34\%; Parnarama - 23,10\%/21,17\% e Paço do Lumiar - 3,61\%/4,35\%). Depreende-se de tal proximidade uma base eleitoral comum, dando maior suporte para compreendermos o papel central de Humberto Coutinho, que articulou alianças em torno dessas duas candidaturas.

Portanto, no ano de 2006, Humberto Coutinho mobilizou a sua rede de apoiadores para eleger a "dobradinha" composta por sua esposa, Cleide Coutinho, e por Flávio Dino, com sucesso. Isso demonstra que, entre os aliados presumidos e a conversão dos mesmos em votos temos a dimensão da "influência" (entendida aqui em termos do potencial para distribuir bens - materiais ou não - nas trocas que estruturam as díades acionadas) aparecendo como elemento central. Ou seja, a possibilidade que determinado agente tem de converter suas relações em votos para outrem se mostra, no caso em pauta, condicionada ao conteúdo destas relações, às expectativas e trocas mútuas, fazendo com que cada um mobilize os recursos que dispõe para agenciar o maior número possível de votos.

É possível observar também que as relações acionadas por Humberto Coutinho para a eleição da "dobradinha" Cleide Coutinho/ Flávio Dino são de caráter multifacetado, envolvendo vinculações de amizade, parentesco e alianças políticas mais pontuais, regidas principalmente pela lógica das fidelidades pessoais, da honra e da "palavra" dada. 


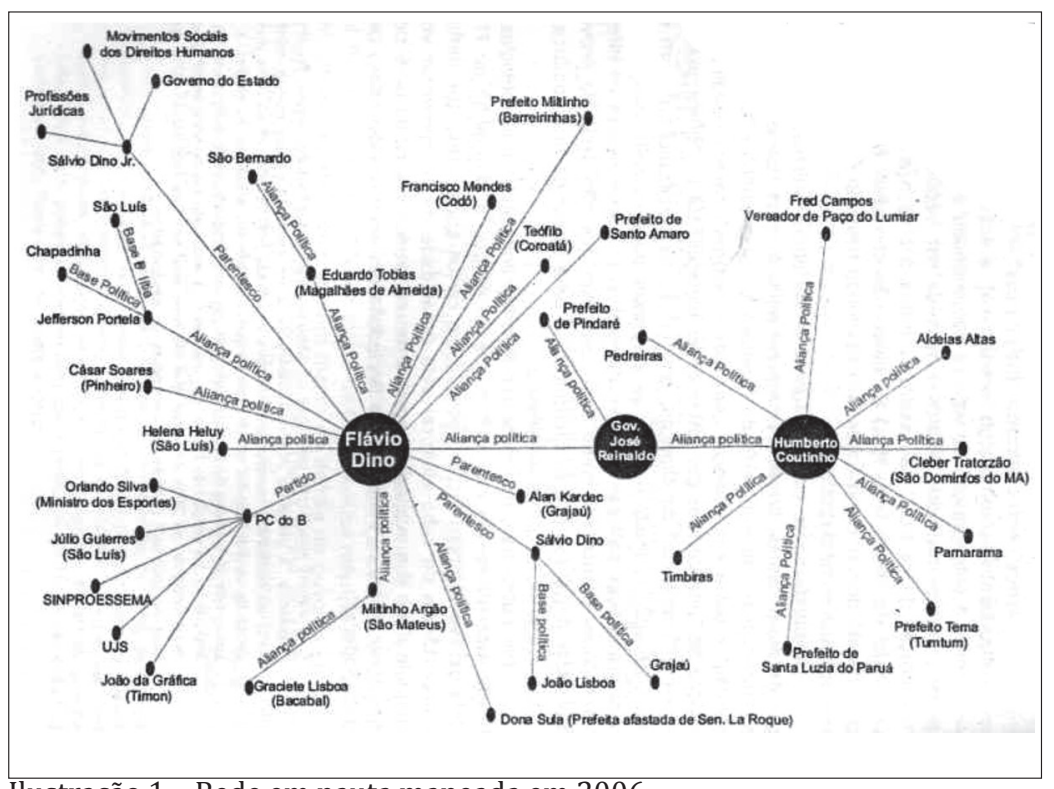

Ilustração 1 - Rede em pauta mapeada em 2006

Fonte: Barros Filho (2008).

Como mais um momento na lógica das retribuições envolvendo agentes situados nos planos municipal e federal (vista aqui a partir da relação entre Humberto Coutinho e Flávio Dino), a eleição municipal de 2008 se configura pela mobilização, desta vez por parte de Humberto Coutinho, do vínculo com Flávio Dino.

Concebido como uma forma de retribuir as verbas liberadas por parte de Flávio Dino para Caxias antes mesmo de se eleger deputado, o empenho de Humberto Coutinho (e o sucesso) para eleger Flávio Dino é também carregado de contrapartidas: as verbas e as obras realizadas no município com sua contribuição durante o seu mandato de deputado federal. Do mesmo modo, outra das contrapartidas ao apoio recebido em 2006 é o uso feito por Humberto da relação com Flávio Dino. Ou seja, o então candidato a prefeito teria condição de conseguir verbas e "fazer as obras que o povo de Caxias precisa". Assim, para o ele, possuir uma aliança com agentes posicionados nos "centros de 
poder" daria condições não apenas de "carrear as verbas" para o município, mas também se converteria numa importante fonte de prestígio e de reconhecimento. A "ponte" com um deputado federal e a importância dada à mesma remete a uma concepção específica da atividade parlamentar, que diz respeito a "ajudar" os municípios, conseguindo recursos para "tocar os projetos".

Esta ênfase nas obras e na possibilidade de "trazer verbas" para o município que encontramos nos materiais de campanha e nas entrevistas realizadas guarda relação com o fato de que a política, para a maioria, não se faz presente e visível a todos de modo contínuo. As obras teriam então esse sentido de dar visibilidade, de "mostrar o trabalho" do político sendo concretamente conduzido. Isto configuraria uma espécie de "patronagem pública" (PALMEIRA, 2006), uma retribuição dada e um favor concedido face aos votos recebidos.

Na última eleição (2010), observa-se essa mesma rede que envolve Humberto Coutinho, Flávio Dino e José Reinaldo Tavares em outro momento, reconfigurada e ampliada, sendo mobilizada em prol de candidaturas.

No início do ano de 2009, por decisão do TSE, Jackson Lago, que havia sido eleito em 2006 pela união das oposições na chamada "Frente de Libertação do Maranhão", teve o seu mandato de governador cassado. Assim, quem assumiu o cargo foi a segunda colocada naquele processo eleitoral, Roseana Sarney. Isto provocou um novo e significativo rearranjo na disposição das alianças e na balança de equilíbrio de poder entre as facções que rivalizavam no plano estadual, a exemplo do que ocorreu a partir da ruptura de José Reinaldo Tavares com a “família” Sarney, em 2006.

Pelo "interior" do estado, muitos prefeitos que em 2006 haviam migrado e passado a apoiar a "Frente" fizeram o movimento oposto em 2009, passando a se vincular novamente à facção da "família" Sarney. A alegação amplamente difundida 
para justificar esses movimentos diz respeito às dificuldades que os prefeitos teriam em governar seus municípios sem os recursos e apoio do governo estadual. Diz-se então que muitos prefeitos foram "obrigados" a fazer esse movimento, pois dependiam da máquina estatal.

Humberto Coutinho talvez tenha sido à época a "liderança" mais representativa do "interior" do estado a não fazer esse "retorno" para a facção liderada pela "família" Sarney, embora tenha se estabelecido um contato inicial entre o prefeito de Caxias e a governadora recém-empossada, que não foi adiante.

Nas eleições de 2010, portanto, Humberto Coutinho novamente articulou outras "lideranças" para eleger seus candidatos, principalmente Flávio Dino, que foi candidato em 2010 ao cargo de governador contra Roseana Sarney. Além dele, José Reinaldo Tavares, responsável por mediar a relação de Humberto/Flávio e amigo de longa data do prefeito de Caxias, foi candidato ao senado ${ }^{21}$.

Nesse quadro de reestruturações significativas nas relações tecidas, alguns prefeitos tidos como grandes aliados de Humberto Coutinho não concederam seu apoio político a este em função da mudança para a coalizão da "família" Sarney. Foi o caso, dentre outros, de Tema Cunha, principal "liderança" da cidade de Tuntum, onde Humberto Coutinho, Cleide Coutinho e Flávio Dino registraram importantes votações em momentos eleitorais distintos, como analisado anteriormente.

Assim como relações políticas foram desfeitas, outras novas foram estabelecidas com protagonistas políticos de outros municípios pelo "interior" do estado por parte de Humberto Coutinho. São cidades que ainda não constavam (pelo menos não com a mesma frequência e relevância) no quadro dos de- 
sempenhos eleitorais dos membros desta coalizão (algumas delas sendo inclusive bases eleitorais importantes para Paulo Marinho, principal rival de Humberto Coutinho em Caxias, em pleitos anteriores): Coelho Neto, Aldeias Altas, São João do Sóter, São Mateus, Sucupira do Norte, Colinas, Mirador e Senador Alexandre Costa.

Algumas das "entradas" nestes municípios, como são denominadas pelos nossos informantes, foram motivadas principalmente para "ajudar" na eleição de Flávio Dino para o governo do estado, declarada a principal meta dessa coalizão naquele processo eleitoral. Essas "entradas" significam, além da constituição de alianças, a instalação de comitês de campanha para Flávio Dino, no intuito de articular as mobilizações em cada cidade.

Com um conjunto de apoiadores relativamente modificado e ampliado a partir da cassação de Jackson Lago e posse de Roseana Sarney no governo do estado em 2009, as eleições de 2010 foram marcadas, de modo semelhante a 2006, pelas viagens conjuntas feitas por Humberto Coutinho, Cleide Coutinho e Flávio Dino por várias cidades, realizando caminhadas ${ }^{22}$ e comícios.

Em um desses eventos, realizado em Caxias e que reuniu várias "lideranças" no palanque, além do prefeito de Caxias, de José Reinaldo Tavares (candidato ao senado), de Cleide Coutinho (candidata a deputada estadual) e de Flávio Dino (candidato ao governo do estado), foram reiterados vários aspectos das vinculações estabelecidas por Flávio Dino com Caxias (e com a região leste do estado) na campanha de 2006 e durante o mandato de deputado federal. Ao tomar a palavra, o candidato atribuiu o seu "nascimento político" à cidade de Caxias:

22 Numa destas, feita em Caxias sem a presença de Flávio Dino, todos os participantes estavam vestindo camisas vermelhas, numa referência à agremiação partidária de Flávio Dino, o PC do B. 
Deus e a minha família me deram a vida, mas quem me deu a vida política foi a cidade de Caxias, foi o povo de Caxias. Há quatro anos atrás, fiz o meu primeiro discurso como um candidato aqui em Caxias. Candidato a deputado federal, na ocasião. Zé Reinaldo era o governador. Humberto Coutinho me trouxe aqui e me apresentou aos vereadores, me apresentou às lideranças políticas, me apresentou a você (...).

No seu pronunciamento diante da cidade do "interior" do estado que lhe rendeu mais votos para deputado federal, Flávio Dino evoca as relações que o fizeram obter tal resultado em 2006. Houve todo um trabalho de apresentação, de tornar sua figura conhecida e reconhecida na cidade.

Por uma atuação marcada pelo "atendimento" às demandas das cidades em que recebeu apoio e votos, as obras e o trabalho na Câmara Federal "pensando nos municípios" aparecem como uma retribuição, um valioso bem que alimenta as relações de reciprocidade que se teceram entre Flávio Dino e Humberto Coutinho, juntamente com as demais "lideranças" que o apoiaram em $2006^{23}$. Esse tipo de relação comporta uma dimensão moral, da honra empenhada na aliança e do "compromisso firmado", não "traindo" a confiança depositada na sua candidatura de 2006.

0 prestígio de Flávio Dino junto à rede de relações articulada em torno de Humberto Coutinho é avaliado pelos seus apoiadores a partir do seu potencial de trânsito na esfera federal, possibilitando direcionar emendas para os mais variados fins. 0 destaque dado à atuação deste agente é explicitado em fórmulas semelhantes a "você pode ver o trabalho de Flávio Dino na sua rua", ou, ainda, como afirma Ferdinando Coutinho: "As obras que tem em Caxias hoje é só do Flávio Dino".

23 Nessa linha, explica Ferdinando Coutinho, irmão de Humberto Coutinho: "O Humberto deu pra ele quase 50 mil votos. Em todos os municípios que foi votado ele também trabalhou, pra responder o voto dele". 
Como um terceiro momento que envolve a atualização da aliança entre Humberto Coutinho e Flávio Dino, alimentada constantemente por esse sistema de contrapartidas (no qual Humberto Coutinho fez a mediação de relações para a ampliação das bases eleitorais de Flávio, enquanto este retribuiu com emendas parlamentares destinadas para os municípios que compõem as relações aqui analisadas), as eleições de 2010 apresentam, em termos de resultados eleitorais, um crescimento geral dos desempenhos de Flávio Dino, comparativamente a 2006 (em que pese as diferenças de uma eleição para o cargo de deputado federal e outra para o cargo de governador). No entanto, alguns resultados poderiam ser classificados como "inesperados", diante da conjuntura política tal como se estruturava em 2010.

Dentre os resultados que poderiam ser classificados como "imprevistos" estão os desempenhos registrados em Matões. Neste município, Flávio Dino apresentou bom desempenho quando comparados os coeficientes de 2006 e 2010.

Muito embora esta cidade seja um importante reduto eleitoral da "família" Coutinho, que possuía alianças com os membros da "família" Pereira, além das posições de vice-prefeito e presidente da Câmara Municipal da cidade que eram à época ocupadas por Edimundo Coutinho e Ferdinando Coutinho (irmãos de Humberto Coutinho), respectivamente, ao que tudo indica estes vínculos não conseguiram se converter em tantos votos quanto se poderia presumir. Isto porque apesar dos seus $41,64 \%$ obtidos na cidade, Flávio Dino foi derrotado neste município por Roseana Sarney em 2010, que teve $52,78 \%$ dos eleitores matoenses depositando seus votos na sua candidatura.

A observação de Fretel e Lagroye (2005) contribui para a compreensão desses resultados aparentemente contraditórios. Eles alertam para certo dedutivismo que cerca as análises de redes sociais e agrupamentos tais como os conjuntos-de-ação e as facções, no que diz respeito à efetividade da conversão concreta de vínculos com apoiadores em coeficientes eleitorais. Isto é, os apoios (reais ou po- 
tenciais) mobilizados nas campanhas pelos candidatos não devem conduzir a uma percepção direta de uma ampla "influência" pura e simplesmente em função desses vínculos. Para estes autores,

se as redes (...) são cadeias de relações mobilizáveis nos conflitos e na concorrência política, a questão que se deve colocar é aquela das condições de sucesso de sua mobilização. Esta só pode dar resultado (...) se os agentes pertencentes têm interesses individuais ou coletivos para se investir fortemente na campanha eleitoral, partilhando uma crença comum na importância da questão e no valor do candidato (...), prontos para aceitar que suas ações sejam politicamente orientadas (FRETEL e LAGROYE, 2005, p.31, grifos nossos).

Desse modo, é preciso também observar a constituição de um conteúdo comum, de uma crença no engajamento (seu e de seus seguidores, no caso de um "grande eleitor"24 ou cabo eleitoral primário) para determinado objetivo, por fim, uma politização das redes, que contribui para melhor captar a força dos interesses dos indivíduos que se encontram inseridos nelas.

\begin{abstract}
Algo semelhante ao ocorrido em Matões pode ser observado em Caxias, ainda que aqui Flávio Dino não tenha perdido para Roseana Sarney. Ocorreu nesta cidade uma inversão na balança de poder que envolve as duas facções que lideram respectivamente as "famílias" Coutinho e Marinho ${ }^{25}$.
\end{abstract}

24 Sobre a noção de "grande eleitor", ver Grill (1999).

25 A facção controlada "família" Marinho, que se opõe localmente à facção que comanda a "família" Coutinho, possui fortes e antigas relações com membros da coalizão da "família" Sarney, o que, no âmbito da cidade de Caxias, acabou por replicar, em 2010, as clivagens estabelecidas no plano estadual (Flávio Dino x Roseana Sarney) por meio destas duas facções. Além disso, Paulo Marinho (principal protagonista político da "família" Marinho) foi deputado federal por três mandatos e prefeito de Caxias. Sua mulher, Márcia Marinho, foi também deputada federal por um mandato e prefeita da mesma cidade de 2000 a 2004. A partir deste último ano, os membros desta "família" que se candidataram observaram uma queda nos seus desempenhos eleitorais na cidade, face às candidaturas da "família" Coutinho. Para uma análise mais detalhada, ver Lima (2012). 
Essa inversão e dominância da "família" Coutinho no cenário político caxiense (e no leste do estado, mais amplamente) poderia facilmente conduzir as expectativas do observador para vitórias largas dos aliados desta "família" em Caxias que concorressem a cargos nos outros níveis da hierarquia política. No entanto, no ano de 2006 (quando Humberto Coutinho já era prefeito de Caxias e contribuiu decisivamente para a eleição de Flávio Dino para deputado federal), Roseana, na sua campanha para o governo, conquistou 49,42\% dos votos dos caxienses. Esse número caiu pouco de 2006 para 2010. Neste último ano, Roseana Sarney teve $44,30 \%$ dos votos, enquanto que Flávio Dino ganhou por uma pequena diferença, atingindo a marca de 45,64\%.

Tal como foi destacado acima, Humberto Coutinho se empenhou em construir novas alianças em outros municípios visando eleger Flávio Dino para o governo. Isso se traduziu na instalação de comitês dedicados principalmente à coordenação da campanha de Flávio Dino. Dessa forma, ocorre uma ligeira expansão da rede, fazendo com que Flávio Dino consiga 14,44\% dos votos de Aldeias Altas, 32,69\% de Colinas, 17,41\% de Mirador, 18,06\% de São João do Sóter, 29,30\% de Sucupira do Norte, 17,29\% de Paraibano e $19,78 \%$ dos votos de Coelho Neto, onde o coordenador das candidaturas apoiadas por Humberto Coutinho em 2010 era Reginaldo Sousa, que é ex-vereador e ex-presidente da Câmara Municipal. Além deste, "Chico da Cola" (também ex-vereador), Vando Galvão e Jardel ("lideranças") faziam parte dos apoiadores envolvidos na eleição dos candidatos de Humberto Coutinho nesta última cidade.

Em 2006, a “dobradinha” foi composta por Flávio Dino e Cleide Coutinho. Esta, por sua vez, foi candidata à reeleição e a candidata com a qual ela fez a "dobradinha" em 2010 foi Nice Lobão, esposa de Edison Lobão (atual ministro das Minas e Energia), que foi, nesse processo eleitoral, candidato ao senado. 0 apoio manifesto aos Lobão aponta para algumas concepções das práticas políticas por parte dos membros da facção liderada pela "fa- 
mília" Coutinho e lança luzes sobre as formas de estruturação de cadeias de líderes-seguidores (LANDÉ, 1977) e sobre as bases sociais e políticas nas quais se desenvolvem as alianças.

\section{A cassação de Jackson Lago e o "corte" de verbas públicas: a constituição de uma "dobradinha"}

Como dito acima, o processo eleitoral de 2010 foi marcado pelos rearranjos resultantes da cassação do governador Jackson Lago e a subsequente posse de Roseana Sarney, em 2009. Como foi possível demonstrar, isso causou modificações significativas no sistema das adesões por parte dos prefeitos para com as facções concorrentes no plano estadual. No caso da rede articulada em torno de Humberto Coutinho, entre os anos de 2006 e 2010 ocorreram rupturas e conquista de novos aliados, principalmente na região leste do estado, expandindo assim a sua "influência" na mesma.

A principal justificativa dada para as migrações dos prefeitos para a coalizão da "família" Sarney por ocasião do retorno de Roseana ao governo é, afirma-se, a "perseguição” sofrida pelos prefeitos que eram aliados de Jackson Lago, Humberto Coutinho e outras lideranças que compuseram, em 2006, a "Frente de Libertação do Maranhão"26. Tal "perseguição" se manifestaria pelo bloqueio de recursos oriundos da máquina estatal para os municípios, dificultando o trabalho das administrações municipais. Isto teria "obrigado" muitos prefeitos a fazer esse movimento, aliando-se à "família" Sarney.

26 É preciso ter em mente as limitações que os materiais impõem à análise. No caso, a principal fonte das informações que servem de base para a descrição dos realinhamentos das forças políticas do estado ocorridos a partir de 2009 constitui-se de entrevistas com membros ou aliados da "família" Coutinho. É preciso então destacar que as interpretações nativas são mobilizadas aqui como um dado importante no que tange à atribuição de significados ao jogo do qual fazem parte os agentes em questão, e não como verdades objetivas desse jogo. Para uma exposição crítica e detalhada dos modos de tratamento de concepções nativas e estruturação das análises na antropologia, ver Geertz (2009). 
Nessa conjuntura de mudanças no poder estadual, o então prefeito de Caxias teria tentado uma aproximação com a nova governadora, que não resultou em acordo. A partir daí, Humberto Coutinho passaria a ser, tal como relataram nossos informantes, alvo das mesmas "perseguições", visando condicionar a sua "mudança de lado" para alinhar-se à facção que agora retomava o governo do estado.

O que se conta é que alguns recursos do governo estadual já estavam garantidos para a cidade e seriam utilizados em saneamento básico e asfaltamento de ruas e avenidas. Como parte dessa "perseguição" imposta pelo governo após a cassação de Jackson Lago, esse dinheiro foi, em expressão frequentemente utilizada por nossos informantes para designar esta ação, "sequestrado" das contas da prefeitura do município. Esse teria sido o mesmo destino dos recursos destinados à saúde de Caxias. Nesse contexto, o retorno de Roseana para o governo estadual é avaliado desta forma por Cleide Coutinho:

Eu vejo com tristeza. Fico triste, porque eu tive conseguido, através de uma emenda, quase $\mathrm{R} \$ 5$ milhões pra saneamento e asfalto. No dia que a Roseana assumiu, o dinheiro dormiu na conta - já tava na conta da prefeitura, já tava licitado -, e não amanheceu. Foi sequestrado o dinheiro. Logo depois, o deputado Ricardo Murad, secretário de saúde, tirou o dinheiro da saúde. E daí pra cá nada conseguimos mais. Então, a gente fica muito triste, não fica sem esperança porque a vida continua e Deus existe, e o prefeito tem um reconhecimento a nível federal, que o que falta no estado, o governo federal tá dando (...).

Novamente, a ênfase nas relações estabelecidas no plano federal aparece como um elemento central para a atuação do gestor municipal, como uma forma de garantir, para além das intempéries da política estadual, a liberação de recursos para suprir as demandas "locais".

Com o estabelecimento do problema relativo aos recursos destinados para a saúde do município, Edison Lobão (amigo e aliado 
de Humberto Coutinho há muitos anos) teria chamado Humberto "para conversar". Nesta ocasião, o prefeito de Caxias relatou a situação do município após o "sequestro" do dinheiro. Por sua vez, Edison Lobão afirmou ser amigo da "segunda pessoa" do Ministério da Saúde, partindo para um telefonema, que teria garantido $\mathrm{R} \$ 250.000$ em recursos para Unidades de Terapia Intensiva e R\$ 3 milhões para compra de remédios.

Esta "ajuda” dada por Edison Lobão contribuiu, tal como é por vezes mencionado, para "salvar a saúde de Caxias", ainda que provisoriamente. Isto foi suficiente para que, como retribuição, tanto Edison Lobão quanto Nice Lobão, sua esposa, recebessem o apoio de Humberto em suas candidaturas para o Senado e para a Câmara Federal em 2010, respectivamente.

As eleições de 2010 não marcam a primeira "dobradinha" feita por um Lobão e um Coutinho, por assim dizer. Em 1998 (época em que Humberto Coutinho ainda pertencia à facção liderada pela "família" Sarney), foi feita a "dobradinha" entre Humberto Coutinho e Nice Lobão, que rendeu a esta 2.778 votos da cidade $(6,73 \%$ do total). No entanto, a "dobradinha" em questão não se repetiu em eleições posteriores porque "foi quando a gente começou a eleger outras pessoas, trabalhar com outras pessoas, né?" [Entrevista com Edimundo Coutinho].

Em 2010, Humberto Coutinho promoveu juntamente com vereadores da cidade de Caxias, Cleide Coutinho e outras "lideranças", caminhadas, comícios, reuniões em residências de "lideranças" de bairros em prol dos seus candidatos. No entanto, pelo menos nos períodos em que realizamos trabalho de campo, Flávio Dino e José Reinaldo não dividiram o palanque com Edison Lobão e Nice Lobão, muito embora aparecessem todos juntos em alguns materiais de campanha. Soma-se a isso o fato de que enquanto Humberto Coutinho mediava relações com políticos de outras cidades para eleger Flávio Dino, José Reinaldo e Cleide Coutinho, o empenho do mesmo em favor das candidaturas de Edison e 
Nice Lobão era restrito a Caxias, já que não obtivemos informações de eventos realizados por Humberto Coutinho em apoio ao casal Lobão fora da cidade.

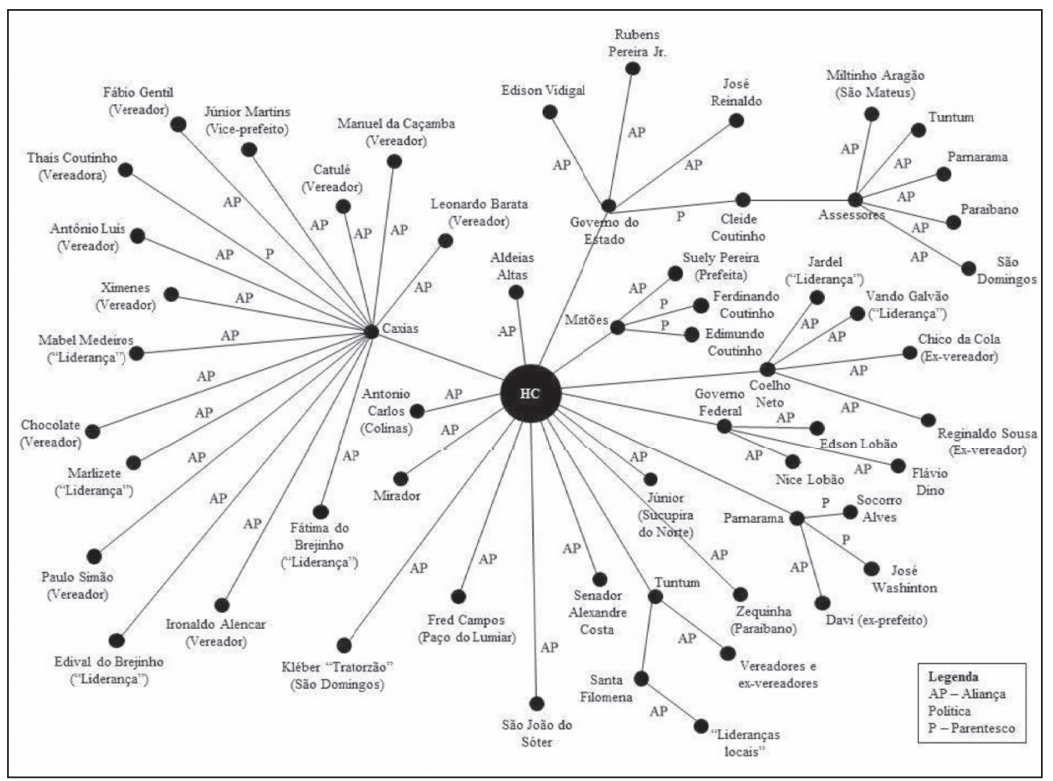

Ilustração 2 - Rede em pauta mapeada em 2010

Os resultados eleitorais de Nice Lobão na cidade de Caxias e nos principais municípios em que Humberto Coutinho possui alianças há algum tempo (tais como São Domingos do Maranhão, Tuntum, Santa Filomena do Maranhão, Parnarama e Matões) nos ajudam a entender o caráter mais "concentrado" desta "dobradinha”, se comparada àquela formada em 2006 por Flávio Dino e Cleide Coutinho.

Após a "dobradinha" entre Humberto Coutinho e Nice Lobão em 1998 , onde pouco mais de $6 \%$ dos votos do eleitorado de Caxias foram destinados a ela, o rendimento obtido nesta eleição não foi observado novamente. Assim, em vez dos 6,73\% dos votos da ci- 
dade conseguidos por Nice quando apoiada por Humberto Coutinho (que à época ainda não era prefeito de Caxias), em 2006, sem o apoio do já prefeito de Caxias, a mesma candidata recebeu apenas $0,26 \%$ dos votos do município. 0 baixo rendimento da sua candidatura em 2006 se fez presente também em redutos eleitorais importantes para os Coutinho, como Matões $(0,08 \%)$, Tuntum (0,18\%), Santa Filomena do Maranhão (0,11\%), Parnarama $(0,11 \%)$ e São Domingos do Maranhão (0,12\%).

Com a "dobradinha" refeita, desta vez entre Nice Lobão e Cleide Coutinho, pode-se compreender melhor essa mobilização mais "concentrada" da rede de Humberto Coutinho para a eleição da esposa de Edison Lobão, que foi mais restrita, portanto, ao município de Caxias.

Com o apoio recebido, Nice Lobão aumentou consideravelmente seu desempenho em Caxias, saindo dos 0,28\% dos votos conquistados em 2006 para 15,44\% em 2010. Este crescimento entre um processo eleitoral e outro não foi observado nos outros municípios que englobam alianças de Humberto Coutinho. Para ilustrar, de 2006 para 2010, as votações de Nice Lobão variaram, respectivamente, da seguinte forma, no que concerne ao eleitorado de cada cidade: Matões (0,08\%/0,46\%), Parnarama (0,11\%/0,20\%), Tuntum (0,18/0,08\%), Santa Filomena do Maranhão (0,11\%/0,05\%) e São Domingos do Maranhão (0,12\%/0,03\%).

Esses baixos rendimentos foram conseguidos concomitantemente às votações obtidas por Cleide Coutinho pelos municípios que englobam a rede de Humberto Coutinho entre estes mesmos processos eleitorais, demonstrando como um conjunto dado de alianças pode efetivamente ser convertido em bases e desempenhos eleitorais, muito embora algumas votações tenham apresentado queda.

Dessa forma, Cleide Coutinho passou, entre 2006 e 2010, de $38,41 \%$ para $49,50 \%$ em Caxias, confirmando esta cidade como 
principal fonte de votos para a "família" Coutinho. Elevação dos índices também foi observada em São Domingos do Maranhão (de 35,41\% para 38,90\%). Os demais apresentaram queda: em Tuntum e Santa Filomena do Maranhão (este último emancipado do primeiro), podemos inferir que as diminuições das votações obtidas possuem relação com a aliança política desfeita com Tema Cunha, principal "liderança" da cidade (ainda que Humberto Coutinho possuísse ligações com vereadores e ex-vereadores deste município). Então, enquanto Cleide Coutinho obteve 48,48\% dos votos de Tuntum em 2006, este número caiu para 22,23\%, e em Santa Filomena do Maranhão a variação foi mais acentuada: passou de $78,12 \%$ para $13,94 \%$.

Mas, de modo um tanto semelhante ao ocorrido com os desempenhos de Flávio Dino na sua campanha para o governo em 2010, Cleide Coutinho recebeu menos votos entre 2006 e 2010 em municípios importantes para esta rede, como Matões (indo de 17,54\% para $5,62 \%$ ), Parnarama (de $23,10 \%$ para $16,78 \%$ ) e Paraibano (de $16,87 \%$ para $12,43 \%)^{27}$. Nos seus desempenhos eleitorais em 2010 ainda aparecem São Mateus e Sucupira do Norte, municípios nos quais, como vimos, foram tecidas alianças mais recentes com suas "lideranças" por parte de Humberto Coutinho em prol da candidatura de Flávio Dino para governador e que acabaram se refletindo em algumas votações para Cleide Coutinho. Na primeira cidade, Cleide Coutinho deteve a parcela de $11,08 \%$ dos votos, enquanto que na segunda a fatia do eleitorado foi de 10,69\%.

Como vemos, as votações de Nice Lobão e Cleide Coutinho se elevaram em Caxias entre as duas campanhas discutidas aqui (sendo o crescimento de Nice Lobão bem mais acentuado), o que corrobora a ideia de uma "dobradinha" mais "pontual", ou seja, mais detida no município de Caxias $^{28}$.

27 Ver Fretel e Lagroye (2005).

28 Edison Lobão foi eleito senador em 2010, tendo recebido 39,01\% dos votos dos eleitores caxienses. 
Retrospectivamente, o apoio dado ao casal Lobão na conjuntura política daquele momento (com Humberto Coutinho sendo um dos principais prefeitos da oposição) fazia mais sentido - e, portanto, tinha maiores condições de ser repassado de modo bem-sucedido ao eleitorado da cidade - quando pensado pelo prisma da gratidão e da retribuição pela liberação dos recursos que "salvaram a saúde de Caxias" e que foram conseguidos, como se afirmava à época, graças à intervenção de Edison Lobão junto ao Ministério da Saúde. Soma-se a isso a necessidade, acima mencionada, sentida pelos prefeitos dos municípios de ter "prestígio" junto ao governo federal.

Apesar de ter uma relativa concentração das suas votações na região leste do estado, o único município que é comum às votações mais representativas de Nice Lobão e Cleide Coutinho é Caxias. Isto indica que estas duas protagonistas políticas dispõem de bases eleitorais distintas e que a elevação da votação de Nice Lobão na cidade está relacionada exclusivamente à constituição da "dobradinha" com Cleide Coutinho, que foi circunscrita aos limites da cidade.

Pelo volume de recursos destinados e o "canteiro de obras" em que se transformou a cidade de Caxias com a contribuição de Flávio Dino junto ao governo federal (como era regularmente apresentado em materiais de campanha), a não candidatura dele à reeleição para o cargo de deputado federal fez com que se concebesse uma perda grande para a cidade, já que seria preciso alguém para substituí-lo, algo considerado difícil pelos nossos informantes, pelo resultado para Caxias do seu mandato de deputado. Mesmo assim, nutrir uma aliança direta com pessoas situadas no plano federal era algo considerado necessário. Diz-se então que o apoio dado para Nice Lobão em Caxias era para que depois fosse possível "cobrar dela" os votos recebidos, em forma de emendas destinadas para o município durante o seu mandato, caso fosse eleita, o que efetivamente aconteceu. 


\section{C onsiderações finais}

Em resumo, o esforço empreendido neste texto resultou de uma tentativa de demonstrar, nos utilizando de variados materiais, como rearranjos faccionais no nível estadual produziram intensas movimentações, rupturas e novas adesões, nas alianças estabelecidas pelas "lideranças" municipais entre si e com agentes situados acima na hierarquia política.

Por meio do movimento efetuado por Humberto Coutinho em conjunto com José Reinaldo Tavares e pela constituição da "Frente de Libertação do Maranhão", pudemos analisar a estruturação das cadeias de líderes-seguidores (LANDÉ, 1977), as bases sobre as quais elas se fundam - enunciadas em geral pelos registros da amizade, da confiança e do prestígio - e os sistemas de retribuições que as regem, bem como os processos de afirmação político-eleitoral do prefeito de Caxias e de sua facção, com a progressiva expansão das suas alianças e bases eleitorais pelo estado, principalmente na região leste, configurando-se atualmente numa importante "liderança" do "interior" do Maranhão ${ }^{29}$.

Com a formação da "dobradinha" entre Nice Lobão e Cleide Coutinho, foram evidenciadas concepções da atividade política, como o pragmatismo das trocas de favores desprovidas, em certa medida, de bases ideológicas, do mesmo modo que o funcionamento dos mecanismos de conversão de alianças em votos.

Dessa forma, por meio dos desempenhos eleitorais ao longo do tempo dos agentes em questão, foi possível demonstrar a já afirmada expansão da rede de relações aqui investigada. Por outro 
lado, observou-se igualmente que uma adesão a determinado "grande eleitor" não necessariamente conduz à sua tradução numa quantidade de sufrágios elevada, como ficou claro pela derrota de Flávio Dino em Matões para Roseana Sarney e a sua vitória apertada em Caxias, do mesmo modo que pela diminuição dos percentuais de votação de Cleide Coutinho nos municípios de Parnarama, Matões e Paraibano.

Retomamos aqui o lembrete feito por Fretel e Lagroye (2005): não basta proceder a uma cartografia das relações em jogo, mas é necessário também atentar para o nível de engajamento de cada um nas mesmas e no quanto elas, por essa via, podem vir a conter certo conteúdo de politização, de crença no candidato apoiado, ultrapassando um pouco a dimensão das trocas clientelísticas vigentes (ou, pelo menos, somando-se a ela).

\section{REFERÊN CIAS BIBLIO GRÁFICAS}

BARROS FILHO, J. A tradição engajada: origens, redes e recursos eleitorais no percurso de Flávio Dino. GRILL, I. G.; REIS, E. T.; BARROS FILHO; J. Elites, Profissionais e Lideranças Políticas (RS e MA): pesquisas recentes. São Luís: EDUFMA, 2008.

BEZERRA, M. O. O "caminho das pedras": representação política e acesso ao governo federal segundo o ponto de vista de políticos municipais. PALMEIRA, M.; BARREIRA, C. Política no Brasil: visões de antropólogos. Rio de Janeiro: Relume-Dumará, 2006.

BOISSEVAIN, J. Second thoughts on quasi-groups, categories and coalitions. Man, vol.6, n.3, 1971.

. Coaliciones. In: SANTOS, F. R. Análisis de redes sociales. Barcelona: Siglo Veintiuno, 2003.

BOURDIEU, P. Modos de dominação. . A produção da crença: contribuição para uma economia dos bens simbólicos. Porto Alegre: Zouk, 2006.

BRIQUET, J.-L.; SAWICKI, F. L’analyse localisée du politique. Politix. Vol. 2, no 7-8, 1989. 
CORADINI, O. L. Processos e resultados eleitorais: um exemplo e um comentário sobre as bases das controvérsias em sua interpretação. Cadernos de Ciência Política, vol.5, 1997.

. As elites como objeto de estudo. Estudos de grupos diri-

gentes no Rio Grande do Sul: algumas contribuições recentes. Porto Alegre: Editora da UFRGS, 2008.

FRETEL, J.; LAGROYE, J. "Faire avec ce qu'on a". Les élections municipales à Rouen. LAGROYE, J; LEHINGE, P; SAWICKI, F. (Orgs.). Mobilisations Électorales: les cas des élections municipales de 2001. Paris: PUF, 2005.

GEERTZ, C. "Do ponto de vista dos nativos": a natureza do entendimento antropológico. In: O saber local. Petrópolis: Vozes, 2009.

GRILL, I. G. As bases sociais dos compromissos: a constituição de um espaço de concorrência eleitoral no Rio Grande do Sul. Dissertação (Mestrado em Ciência Política), Universidade Federal do Rio Grande do Sul. Porto Alegre, 1999.

. "Família", configuração de apoios e atendimento no percurso de um "herdeiro político". . "Heranças Políticas" no Rio Grande do Sul. São Luís: EDUFMA, 2008.

LAGROYE, J. De l'objet local à l'horizon local des pratiques. MABILEAU, M. (Org.). A la recherche du local. Paris: L'Hartmattan, 1993.

. Être du métier. Politix. Vol. 7, no 28, 1994.

LANDÉ, C. H. Groups politics and dyadic politics: notes for a theory. SCHMIDT, S. W. et alli. (Eds.). Friends, Followers and Factions. A reader in political clientelism. Berkeley, University of California Press, 1977.

LIMA, J. G. N. Seleção de "elites locais" e a dinâmica de concorrência eleitoral em Campos (MA). GRILL, Igor Gastal et alli (Orgs.). Eleições municipais no Maranhão. São Luís: EDUFMA, 2010.

. Diversificação de papéis e divisão do trabalho político especializado: análise a partir de uma "família de políticos" do Maranhão. Dissertação (Mestrado em Ciências Sociais) - Centro de Ciências Humanas, Universidade Federal do Maranhão. São Luís, 2012.

MARQUES, A. C. Algumas faces de outros eus: honra e patronagem na antropologia do mediterrâneo. Mana, vol.5, n.1, 1999.

MAYER, A. A importância dos quase-grupos no estudo das sociedades complexas. FELDMAN-BIANCO, Bela. (org.). Antropologia das sociedades contemporâneas. São Paulo: Global, 1987. 
PALMEIRA, M. Política, facções e voto. GOLDMAN, Márcio (Orgs.). Antropologia, voto e representação política. Rio de Janeiro: Contra-Capa Livraria, 1996.

Eleição municipal, política e cidadania. PALMEIRA, M.; BARREIRA, C. (Orgs.). Política no Brasil: visões de antropólogos. Rio de Janeiro: Relume-Dumará, 2006.

VELHO, G.; KUSCHNIR, K. Mediação e metamorfose. KUSCHNIR, K. Eleições e representação política no Rio de Janeiro. Rio de Janeiro: Relume Dumará, 2000 .

WEINGROD, A. Patronazgo y poder. GELLNER, E. et alli (Orgs.). Patronos y clientes en las sociedades mediterráneas. Madrid: Jucar, 1986.

WOLF, E. Aspectos das relações de grupos em uma sociedade complexa: México. . Antropologia e poder: contribuições de Eric R. Wolf. Brasília:

Ed. UnB; São Paulo: Imprensa Oficial; Campinas: Ed. Unicamp, 2003a.

. Parentesco, amizade e relações patrono-cliente em sociedades complexas. . Antropologia e poder: contribuições de Eric. R. Wolf. Brasília: Ed. UnB; São Paulo: Imprensa Oficial; Campinas: Ed. Unicamp, 2003b.

Data de Recebimento: 12 de dezembro de 2014

Data de Aprovação: 30 de dezembro de 2014 